\title{
Prognostic impact of clinical course-specific mRNA expression profiles in the serum of perioperative patients with esophageal cancer in the ICU: a case control study
}

Shunsaku Takahashi ${ }^{1,2}$, Norimasa Miura ${ }^{2 *}$, Tomomi Harada ${ }^{1,2}$, ZhongZhi Wang $^{2}$, Xinhui Wang ${ }^{2}$, Hideyuki Tsubokura ${ }^{3}$, Yoshiaki Oshima ${ }^{1,4}$, Junichi Hasegawa ${ }^{2}$, Yoshimi Inagaki ${ }^{1}$, Goshi Shiota ${ }^{5}$

\begin{abstract}
Background: We previously reported that measuring circulating serum mRNAs using quantitative one-step realtime RT-PCR was clinically useful for detecting malignancies and determining prognosis. The aim of our study was to find crucial serum mRNA biomarkers in esophageal cancer that would provide prognostic information for postesophagectomy patients in the critical care setting.

Methods: We measured serum mRNA levels of 11 inflammatory-related genes in 27 post-esophagectomy patients admitted to the intensive care unit (ICU). We tracked these levels chronologically, perioperatively and postoperatively, until the two-week mark, investigating their clinical and prognostic significance as compared with clinical parameters. Furthermore, we investigated whether gene expression can accurately predict clinical outcome and prognosis.

Results: Circulating mRNAs in postoperative esophagectomy patients had gene-specific expression profiles that varied with the clinical phase of their treatment. Multivariate regression analysis showed that upregulation of IL-6, WWF and TGF- $\beta 1$ mRNA in the intraoperative phase $(p=0.016,0.0021$ and 0.009$)$ and NAMPT and MUC1 mRNA on postoperative day $3(p<0.01)$ were independent factors of mortality in the first year of follow-up. Duration of ventilator dependence (DVD) and ICU stay were independent factors of poor prognosis $(p<0.05)$. Therapeutic use of Sivelestat (Elaspol ${ }^{\oplus}$, Ono Pharmaceutical Co., Ltd.) significantly correlated with MUC1 and NAMPT mRNA expression ( $p=0.048$ and 0.045). IL-6 mRNA correlated with hypercytokinemia and recovery from hypercytokinemia (sensitivity $80.9 \%$ ) and was a significant biomarker in predicting the onset of severe inflammatory diseases.

Conclusion: Chronological tracking of postoperative mRNA levels of inflammatory-related genes in esophageal cancer patients may facilitate early institution of pharamacologic therapy, prediction of treatment response, and prognostication during ICU management in the perioperative period.
\end{abstract}

\section{Background}

Esophageal cancer is one of the most aggressive malignant tumors of the digestive tract. Post-esophagectomy anastomotic leak and pneumonia are common and can lead to acute respiratory distress syndrome (ARDS). Acute respiratory distress syndrome (ARDS) is a diffuse

\footnotetext{
* Correspondence: mnmiura@med.tottori-u.ac.jp

${ }^{2}$ Division of Pharmacotherapeutics, Department of Pathophysiological and Therapeutic Science, Faculty of Medicine, Tottori University, Nishicho 86, Yonago, Tottori 683-8503, Japan

Full list of author information is available at the end of the article
}

heterogeneous lung disease resulting in progressive hypoxemia due to ventilation/perfusion mismatching and intrapulmonary shunting. Its causes are diverse and it is associated with a near $100 \%$ mortality after 48 hours $[1,2]$. Ventilator-induced acute lung injury (ALI) is known to cause diffuse parenchymal damage secondary to alveolar overdistension, bacterial translocation and cytokine release $[3,4]$. Detailed, sequential assessment of organ dysfunction during the first 48 hours of ICU admission is a reliable indicator of prognosis [5]. 
Recently, the use of gene-expression profiling on a transcriptome level of peripheral blood mononuclear cells (PBMC) identifies signature genes that distinguish severe sepsis (SS) from noninfectious causes of systemic inflammatory response syndrome (SIRS), sepsis-related immunosuppression and reduced inflammatory response [6]. SS has been categorized as a subset of SIRS resulting from hypercytokinemia [7]. As there are currently no reliable genetic markers for use in ICU care and prognostication, we aimed to determine the clinical value of measuring circulating RNA in the serum of ICU patients [8]. Since circulating RNA remains stable for approximately 24 hours, its detection may reflect early changes in clinical status and may make it possible to predict morbidity and survival [9].

We previously reported that the measurement of human telomerase reverse transcriptase gene (hTERT) mRNA in serum is useful for the diagnosis of some malignancies. We also found that serum transforming growth factor- $\alpha$ mRNA is useful as a prognostic indicator in fulminant hepatitis in patients without encephalopathy upon admission $[10,11]$. In the present study, we examined 11 proinflammatory genes in patients receiving therapy in the ICU following surgery for esophageal cancer: matrix metallopeptidase 9 (MMP9), which reflects the activity of neutrophils and correlates with survival in patients with esophageal cancer [12-14]; early growth response 1 (EGR1), as a transcriptional regulator in ALI [15-17]; high-mobility group box 1 (HMGB1), as a candidate proinflammatory factor predicting the prognosis of SIRS [18-20]; mucin1 (MUC1), as both an independent predictor for intravascular coagulation in ARDS and a biomarker for esophageal cancer [21-23]; nicotinamide phosphoribosyltransferase (NAMPT/PBEF1), as a regulator in new inflammatory networks [24-27]; platelet-derived growth factor alpha polypeptide (PDGFA), which is involved in alveolar septal formation [28-30]; transforming growth factor beta 1 (TGF- $\beta 1$ ), as an activator of procollagen $I$ in patients with acute lung injury (ALI) [31-33]; tumor necrosis factor-alpha (TNF- $\alpha$ ), as a prognostic determinant of ARDS in adults [34-36]; von Willebrand factor (VWF), as an independent marker of poor outcome in patients with early ALI [37-39]; and interleukin 6 (IL-6), which is upregulated in inflammation and promotes the maturation of B cells [40]. Lung injury-related genes (HMGB1, MUC1 and VWF), proinflammation-related genes (MMP, CRP, and HMGB1), coagulation-related genes, immunoreactive genes (PBEF1 and TNF- $\alpha$ ), fibrosis-related gene (TGF- $\beta$ ), wound-healing related gene (PDGFA), and cancerrelated genes (MUC1 and hTERT) have been reported previously to correlate with the onset of ARDS or SIRS and subsequent survival. ARDS and SIRS seriously affect the prognosis of postoperative patients. Anastomotic leak and pneumonia extend the length of ICU stay and duration of ventilator dependence, resulting in a poorer prognosis. We investigated the clinical significance and prognostic usefulness of measuring serum levels of mRNA of these genes chronologically from ICU admission in patients treated surgically for esophageal cancer.

\section{Methods}

\section{Patients and sample collection}

27 patients who underwent radical surgery for esophageal cancer at Tottori University Hospital, Tottori Red Cross Hospital and Shimane Prefectural Central Hospital, between January 2006 and December 2008, were prospectively studied (Tables 1,2). All patients were admitted to the ICU after operation as per our department/Tottori University protocol. The patients were discharged from the ICU when stable according our critical care departmental criteria.

We measured serum mRNA levels for 14 days postoperatively. Informed consent was obtained from each patient and study protocols followed standard ethical guidelines (Declaration of Helsinki, 1975) and were approved by the institutional review board of Tottori University (approval no.138, no 138 1, 2001; no. 343, 2009). The patients consisted of 3 females (mean age 67.3 years, age range 49 to 82 years) and 24 males (mean age 65 years, age range 40-76). All patients were classified as American Society of Anesthesiologists (ASA) physical status 1 or 2 . Patients were prospectively followed for 12 months postoperatively. SIRS or ARDS were diagnosed according to accepted consensus definitions [41,42]. Clinicopathological findings, such as age, diagnosis, etiology, prognosis, effect of the neutrophil elastase inhibitor sivelestat $(4.8 \mathrm{mg} / \mathrm{kg} /$ day $)$, total days of ventilator dependence (DVD), total days of ICU stay, preoperative CRP levels (preCRP), CRP levels at postoperative day (POD) 1 , peak concentrations of CRP (peak CRP), operation duration, anesthesia duration, $\mathrm{PaO}_{2} / \mathrm{FiO}_{2}$ ratio at POD 1, days of SIRS, sequential organ failure assessment (SOFA) scores at POD 1, and mortality at 30 days, 6 months, and 1 year were recorded.

Anesthesia consisted of general anesthesia and epidural anesthesia. After surgery, all patients were reintubated with single-lumen endotracheal tubes from the doublelumen endotracheal tubes used intraoperatively and received ventilator support in ICU. Serum from whole blood was obtained intraoperatively and on POD 1, POD 3, POD 5 and POD 14. We measured serum mRNA levels of 11 genes (MMP9, CRP, HMGB1, MUC1, EGR1, PBEF1, PDGFA, TGF- $\beta 1$, TNF- $\alpha$, VWF, and IL-6). Sivelestat was prophylactically administered intravenously by the judgment of the attending physician and according to the manufacturer's recommendations. We distinguished SIRS from severe non-infectious systemic inflammatory 
Table 1 Patient Demographics in ICU After Surgical Treatment of Esophageal Cancer

\begin{tabular}{|c|c|c|c|c|c|c|c|c|c|c|c|c|c|}
\hline $\begin{array}{l}\text { Pt. } \\
\#\end{array}$ & $\begin{array}{l}{ }^{*} \text { Con } / \\
\text { Siv }\end{array}$ & DVD & $\begin{array}{l}\text { ICU } \\
\text { stay }\end{array}$ & $\begin{array}{l}\text { Operation } \\
\text { time }\end{array}$ & $\begin{array}{l}\text { Anesthesia } \\
\text { time }\end{array}$ & $\begin{array}{l}\mathrm{PaO} 2 / \\
\text { FiO2 ratio } \\
\text { (POD1) }\end{array}$ & SIRS & $\begin{array}{l}\text { SOFA } \\
\text { scores } \\
\text { (POD1) }\end{array}$ & $\begin{array}{l}\text { Anastomotic } \\
\text { Leak }\end{array}$ & Pneumonia & $\begin{array}{l}\text { Mortality } \\
\text { (-30D) }\end{array}$ & $\begin{array}{l}\text { Mortality } \\
(-6 M)\end{array}$ & $\begin{array}{l}\text { Mortality } \\
(-1 Y)\end{array}$ \\
\hline$\# 1$ & Siv & 2 & 3 & 765 & 856 & 211.3 & 2 & 3 & +(POD8) & - & alive & alive & dead \\
\hline \#2 & Siv & 2 & 2 & 510 & 560 & 272.5 & 6 & 5 & - & $+(\mathrm{POD} 3)$ & alive & alive & dead \\
\hline \#3 & Con & 0 & 2 & 270 & 343 & 125 & 1 & 4 & - & - & alive & alive & alive \\
\hline \#4 & Siv & 2 & 2 & 555 & 638 & 148.8 & 0 & 3 & $+(\mathrm{POD} 5)$ & - & alive & alive & alive \\
\hline \#5 & Con & 2 & 6 & 233 & 370 & 220 & 0 & 7 & - & - & alive & alive & alive \\
\hline \#6 & Con & 7 & 6 & 930 & 1025 & 302.5 & 4 & 5 & +(POD9) & $+(\mathrm{POD} 7)$ & alive & alive & alive \\
\hline \#7 & Siv & 2 & 3 & 525 & 565 & 148 & 2 & 4 & $+(\mathrm{POD} 5)$ & - & alive & alive & alive \\
\hline \#8 & Con & 0 & 4 & 285 & 400 & 246 & 1 & 2 & - & - & alive & alive & alive \\
\hline \#9 & Siv & 2 & 12 & 467 & 580 & 206 & 5 & 5 & $+(\mathrm{POD} 6)$ & - & alive & alive & alive \\
\hline$\# 10$ & Con & 2 & 3 & 681 & 573 & 194.3 & 8 & 5 & $+(\mathrm{POD} 5)$ & - & alive & alive & dead \\
\hline \#11 & Siv & 74 & 74 & 615 & 682 & 190 & 31 & 6 & $+(\mathrm{POD} 5)$ & $+(\mathrm{POD} 2)$ & alive & dead & dead \\
\hline$\# 12$ & Con & 2 & 3 & 491 & 598 & 184 & 2 & 6 & - & - & alive & alive & alive \\
\hline$\# 13$ & Con & 2 & 3 & 487 & 570 & 212 & 1 & 3 & $+(\mathrm{POD} 5)$ & - & alive & alive & alive \\
\hline$\# 14$ & Con & 6 & 7 & 543 & 630 & 447.5 & 7 & 2 & - & $+(\mathrm{POD} 3)$ & alive & alive & alive \\
\hline$\# 15$ & Siv & 0 & 0 & 415 & 505 & 213.8 & 3 & 2 & - & - & alive & alive & alive \\
\hline$\# 16$ & Siv & 3 & 16 & 551 & 695 & 272.2 & 1 & 6 & $+(\mathrm{POD} 5)$ & - & dead & dead & dead \\
\hline$\# 17$ & Con & 2 & 3 & 645 & 715 & 244 & 7 & 5 & $+($ POD7) & - & alive & alive & alive \\
\hline$\# 18$ & Siv & 11 & 13 & 547 & 602 & 277.5 & 2 & 4 & - & - & alive & alive & alive \\
\hline \#19 & Siv & 3 & 4 & 520 & 564 & 342.5 & 1 & 4 & - & - & alive & alive & alive \\
\hline$\# 20$ & Siv & 3 & 4 & 698 & 775 & 397.5 & 1 & 6 & $+($ POD12) & $+(\mathrm{POD} 3)$ & alive & alive & alive \\
\hline \#21 & Con & 6 & 7 & 657 & 760 & 360 & 3 & 4 & - & $+(\mathrm{POD6})$ & alive & alive & alive \\
\hline$\# 22$ & Siv & 4 & 6 & 1305 & 1375 & 187.5 & 1 & 9 & - & - & alive & alive & alive \\
\hline \#23 & Con & 2 & 3 & 735 & 820 & 257 & 5 & 2 & - & $+($ POD7) & alive & alive & alive \\
\hline$\# 24$ & Con & 3 & 8 & 724 & 795 & 252 & 2 & 5 & - & - & alive & alive & alive \\
\hline$\# 25$ & Con & 1 & 5 & 525 & 580 & 216 & 1 & 2 & $+(\mathrm{POD} 5)$ & - & alive & alive & alive \\
\hline \#26 & Con & 5 & 7 & 254 & 345 & 245 & 0 & 5 & - & - & alive & alive & alive \\
\hline$\# 27$ & Siv & 3 & 8 & 572 & 629 & 257.5 & 5 & 6 & - & $+(\mathrm{POD} 4)$ & alive & alive & alive \\
\hline
\end{tabular}

Pt \#: patient number, * con: conventional therapy, Siv: Sivelestat. DVD; duration of ventilator dependence.

response syndrome (SNISIRS) by examining gene expression (GE) in the serum and synchronizing GE changes with the clinical course of events.

Processing of the blood and serum samples was performed after blood sampling during the operation and at POD 1, POD 3, POD 5 and POD 14. mRNA quantification was performed as previously described [43]. RNA extraction and real-time RT-PCR RNA was performed after DNase treatment, also reported previously [43-45]. In brief, RNA from $200 \mu \mathrm{l}$ of serum was dissolved in $200 \mu \mathrm{l}$ of $\mathrm{H}_{2} \mathrm{O}$. RT-PCR was performed using $1 \mu \mathrm{l}$ of RNA extract and $2 \mu \mathrm{l}$ of SYBR Green I (Roche, Basel, Switzerland) in a one-step RT-PCR kit (Qiagen, Tokyo, Japan). RNA was extracted from blood using the same volume of serum concentrated 20-fold (Invitrogen Corp., Carlsbad, CA, USA). RT-PCR conditions were: incubation at $50^{\circ} \mathrm{C}$ for $30 \mathrm{~min}$ followed by incubation for $12 \mathrm{~min}$ at $95^{\circ} \mathrm{C}$ for denaturation, then 50 cycles at $95^{\circ} \mathrm{C}(0 \mathrm{~s})$, annealing at $50-55^{\circ} \mathrm{C}(10 \mathrm{~s})$ and $72^{\circ} \mathrm{C}(15 \mathrm{~s})$, and extension at $40^{\circ} \mathrm{C}(20 \mathrm{~s})$. All primers were optimally designed (INTEC Web \& Genome Informatics Corp.,
Tokyo, Japan). The final concentration of the primers was $1 \mu \mathrm{M}$; sequences are shown in Table 3 . The dynamic range of the real-time PCR analysis for each mRNA was more than 5-10 copies in this assay, but we semi-quantitatively measured 11 gene expression profiles of interest as relative expression levels against $\beta$-actin mRNA [46]. The RT-PCR assay was repeated twice and quantification was reproducibly confirmed with LineGene (TOYOBO, Tokyo, Japan). We confirmed that the amplicons were derived from the gene of interest by Western blot. IL-6 protein level was measured using an ELISA kit according to the manufacturer's instruction (R\&D Systems, MN, USA). SOFA was scored according to international criteria [47].

\section{Statistical Analysis}

Clinical parameters and gene expression profiles were statistically evaluated using SPSS 13.0 (SPSS Japan Inc., an IBM company, 2004). Multivariate regression analysis was performed with respect to prognosis weighted at 30 days, 6 months and 12 months or with stepwise selection. 
Table 2 Gene Expression Data for Esophageal Cancer Patients in the ICU After POD 14

\begin{tabular}{|c|c|c|c|c|c|c|}
\hline Pt.\# & $\begin{array}{c}\mathrm{SCC} \\
\text { (ng/mL) }\end{array}$ & $\begin{array}{l}\text { Cytokeratin fragment } 19 \\
(\mathrm{ng} / \mathrm{mL})\end{array}$ & $\begin{array}{c}\text { CEA } \\
\text { (ng/mL) }\end{array}$ & $\begin{array}{c}\text { hTERTmRNA } \\
\text { (logarithmic copy number) }\end{array}$ & Recurrence & $\begin{array}{l}\text { Depth of tumor } \\
\text { invasion }\end{array}$ \\
\hline$\# 1$ & 2.4 & 2.5 & - & 3.31 & - & $M p$ \\
\hline$\# 2$ & - & - & - & 3.9 & - & $\mathrm{Sm}$ \\
\hline \#3 & 0.9 & 1.5 & - & 2.96 & + & Ss \\
\hline$\# 4$ & $<0.5$ & 1.4 & - & 4.41 & - & $\mathrm{Sm}$ \\
\hline \#5 & - & - & - & 0 & - & M \\
\hline \#6 & 2.0 & 1.6 & - & 0 & + & Ss \\
\hline \#7 & 0.9 & 0.9 & - & 4.96 & - & $\mathrm{Sm}$ \\
\hline \#8 & $<0.5$ & 1.9 & - & 0 & - & Ss \\
\hline$\# 9$ & 1.1 & 1.3 & 3.8 & 2.97 & - & Ss \\
\hline$\# 10$ & 1.2 & 2.1 & 1.0 & 3.58 & - & Ss \\
\hline$\# 11$ & - & - & - & 2.75 & - & Ss \\
\hline$\# 12$ & 0.8 & 0.9 & - & 2.14 & - & Ss \\
\hline$\# 13$ & 1.6 & 2.7 & 1.4 & 4.61 & - & $\mathrm{Sm}$ \\
\hline$\# 14$ & 2.7 & - & 3.1 & 3.99 & - & Ss \\
\hline$\# 15$ & 0.9 & 3.0 & - & 3.84 & - & Ss \\
\hline$\# 16$ & - & - & - & 3.81 & - & $\mathrm{Sm}$ \\
\hline$\# 17$ & 1.6 & 7.4 & - & 4.14 & - & $M p$ \\
\hline$\# 18$ & 1.3 & 0.9 & 2.4 & 4.53 & - & $\mathrm{Sm}$ \\
\hline$\# 19$ & 0.7 & 2.5 & - & 4.11 & - & $\mathrm{Sm}$ \\
\hline$\# 20$ & 3.9 & 3.1 & 2.4 & 4.41 & - & Ss \\
\hline$\# 21$ & 2.9 & - & 3.5 & 3.44 & - & $\mathrm{Mp}$ \\
\hline$\# 22$ & 0.7 & 2.2 & - & 4.35 & - & $\mathrm{Sm}$ \\
\hline$\# 23$ & $<0.5$ & 1.4 & - & 4.03 & - & Ss \\
\hline$\# 24$ & 1.4 & - & - & 3.89 & - & $M$ \\
\hline$\# 25$ & 1.2 & 1.4 & - & 3.35 & - & Ss \\
\hline$\# 26$ & - & - & - & 4.39 & - & $M$ \\
\hline$\# 27$ & 0.7 & 0.9 & 2.3 & 4.45 & - & $\mathrm{Mp}$ \\
\hline
\end{tabular}

-: not measured.

In addition, we tested the effects of sivelestat, polymyxin B-immobilized fiber column (PMX), and factors predicting the development anastomotic leak or pneumonia against clinical course and gene expression by one-way ANOVA. To assess the accuracy of the prognostic factors (medication use, gene function in the acute phase, and ventilatory regulation), the correlation of each factor with prognosis was evaluated using receiver operator characteristic (ROC) curve analyses. A predictive cut-off value was evaluated as the nearest point from the left upper edge of the ROC curve analysis graph. Sensitivity was calculated as the mean confidence interval (CI) of the area

Table 3 Primer Sets Used for Each Gene Investigated

\begin{tabular}{llll}
\hline Gene & GenBank Accession No. & Forward Primer & Reverse Primer \\
\hline WWF & NM_000552.2 & TGA CCA GGT TCT CCG AGG AG & CAC ACG TCG TAG CGG CAG TT \\
TGFB1 & MN_000660.3 & GAC TAC TAC GCC AAG GAG GT & GGA GCT CTG ATG TGT TGA AG \\
PDGFA & MN_002607.5 & GGG AGT GAG GAT TCT TTG GA & AAA TGA CCG TCC TGG TCT TT \\
NAMPT & MN_005746.2 & CTG TTC CTG AGG GCA TTG TC & GGC CAC TGT GAT TGG ATA CC \\
CRP & MN_000567.2 & ACA GTG GGT GGG TCT GAA AT & TAC CCA GAA CTC CAC GAT CC \\
EGR1 & MN_001964.2 & TTC TTC GTC CTT TTG GTT TA & AAG GCT AGA GGT GAG CA \\
HMBG1 & MN_002128.4 & AAC CAC CCA GAT GCT TCA GT TाT GCC ATA TCT TC \\
TNF- $\alpha$ & MN_000594.2 & TGC TTG TTC CTC AGC CTC TT & GCA CTC ACC TCT TCC CTC TG \\
MUC1 & MN_001018016.1 & CCT CTG AAG GAG GCT GTG AT \\
MMP9 & NM_004994.2 & CCA TTC CAC TCC ACT CAG GT & CCC TCA GTC AAG CGC TAC AT \\
IL-6 & MN_000600.3 ACA GCG ACA AGA AGT GG & TAA AGC TGC GCA CAA TGA GA \\
$\beta$-actin & MN_031144.2 & ATG CAA TAA CCA CCC CTG AC & GCA GCC GTG GCC ATC TCT TG \\
\hline
\end{tabular}


under the curve (AUC) and specificity was calculated in the output table of the ROC. To estimate survival, Kaplan-Meier analysis was performed. P values less than 0.05 were considered statistically significant.

\section{Results}

\section{Circulating mRNA expression during hospitalization}

The mRNA expression profiles over the 14 days are shown in Figure 1. MMP9 and NAMPT (PBEF1) were similar in that both were upregulated from POD 5 onwards. VWF and TGF- $\beta 1$ demonstrated similar upregulation from POD 3. At POD 1, CRP mRNA upregulation was accompanied by increased serum CRP levels; these decreased at POD 3 following appropriate treatment (data not shown). MUC1 and PDGFA were upregulated at POD 3 ( $\mathrm{p}=0.048$ and 0.045 ), followed by recovery from POD 5 to POD 14 . IL-6 was upregulated at POD 5 then decreased to the intraoperative baseline value. EGR1 and HMGB1 levels gradually decreased from the intraoperative values to baseline at POD 14.

Two mRNAs of proinflammatory genes seen in ALI (HMGB1 and VWF) changed similarly $(\mathrm{p}=0.021)$. CRP mRNA correlated with conventional CRP levels ( $\mathrm{p}=$ 0.029 and 0.004 ). Primers designed for amplifying CRP mRNA did not detect inflammation with more sensitivity than conventional CRP. However, CRP mRNA correlated with CRP levels at PODs 1,3 , and $14(\mathrm{p}=0.009$, 0.02 , and 0.009). Sensitivities and specificities of mRNA levels as prognostic indicators of clinical course are shown (Additional File 1). With respect to gene markers' association with surgical parameters, upregulation of TNF- $\alpha$ mRNA correlated with increased duration of anesthesia ( $\mathrm{p}=0.023)$; and VWF upregulation with increased duration of surgery $(p=0.025)$. MMP9

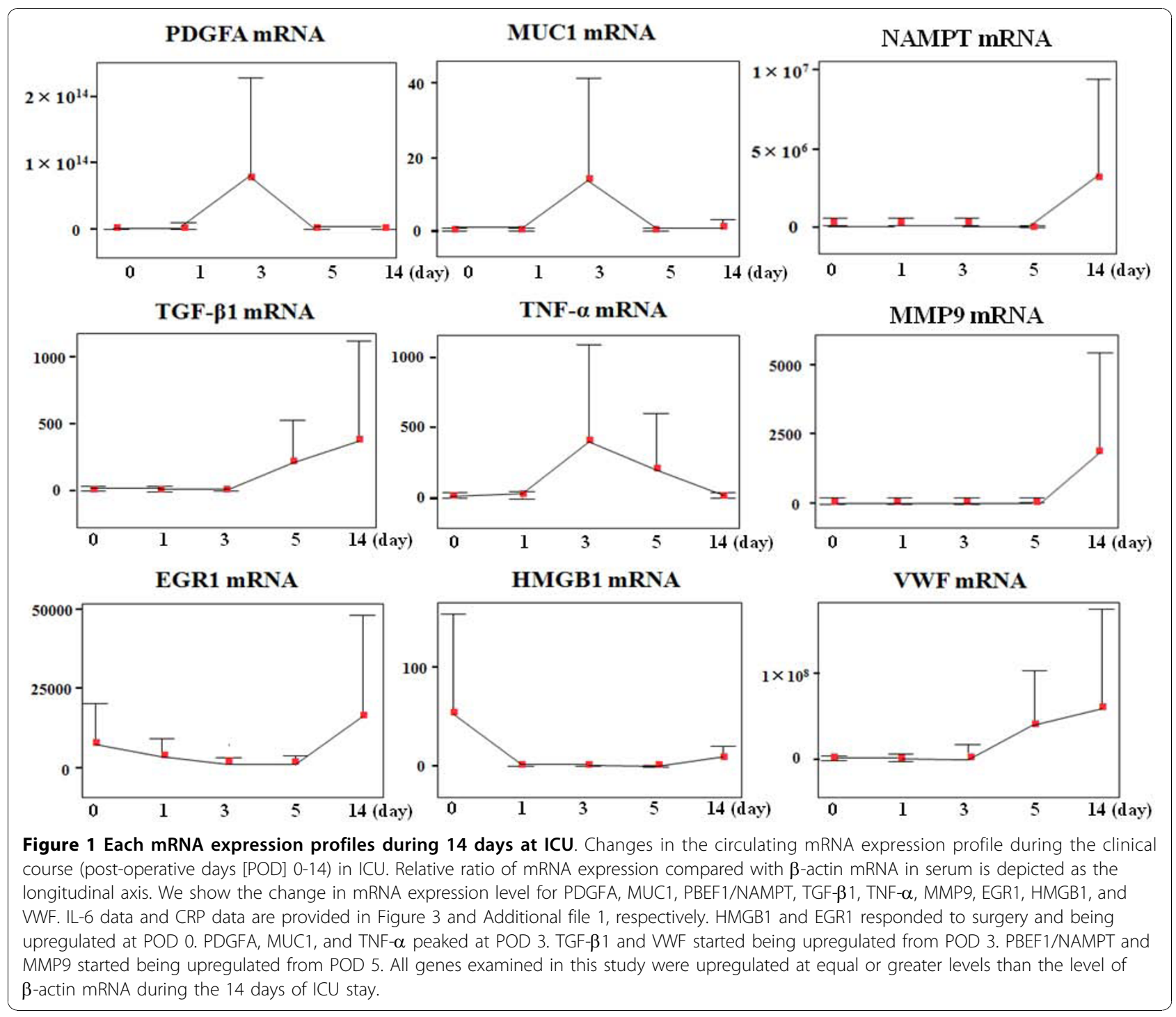


mRNA expression correlated with PDGFA mRNA up to POD 14 ( $\mathrm{p}=0.007)$ and treatment with sivelestat altered MUC1 expression ( $p=0.024$, Figure $2 b$ ). TNF- $\alpha$ mRNA expression correlated with duration of SIRS ( $\mathrm{p}=$ 0.042). CRP mRNA expression correlated with length of ICU stay, which in turn was associated with 6-month mortality $(\mathrm{p}=0.033$ and 0.016$)$.
Prognostic factors in the perioperative period

We found IL- 6 mRNA to be a significant marker of prognosis (Figure 3b, c). IL-6 mRNA was upregulated in the immediate perioperative period (POD 0, Figure 3a) and gradually decreased at POD 3. Conversely, IL-6 levels increased postoperatively. The AUC of IL-6 mRNA and IL- 6 was 0.809 and 0.453 , respectively, and

(a) Kaplan-Meier survival analysis
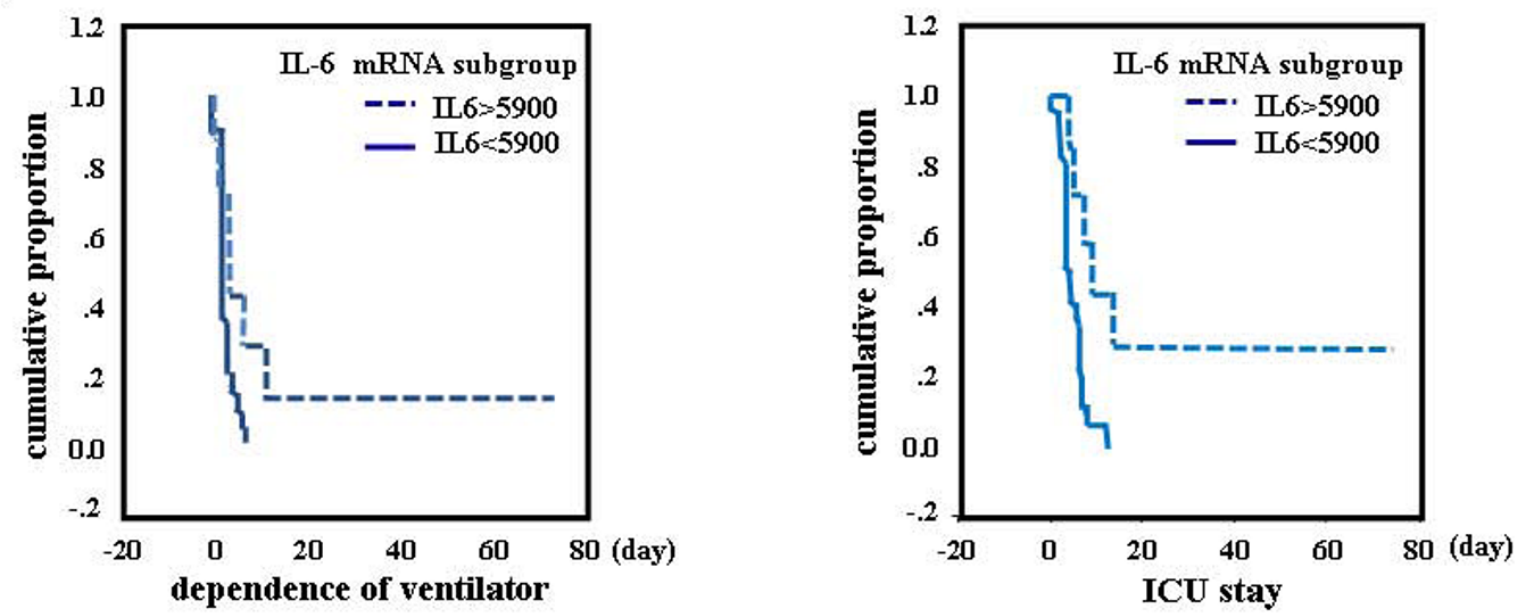

(b) Sivelestat or PMX-treated effect on MUC1 mRNA
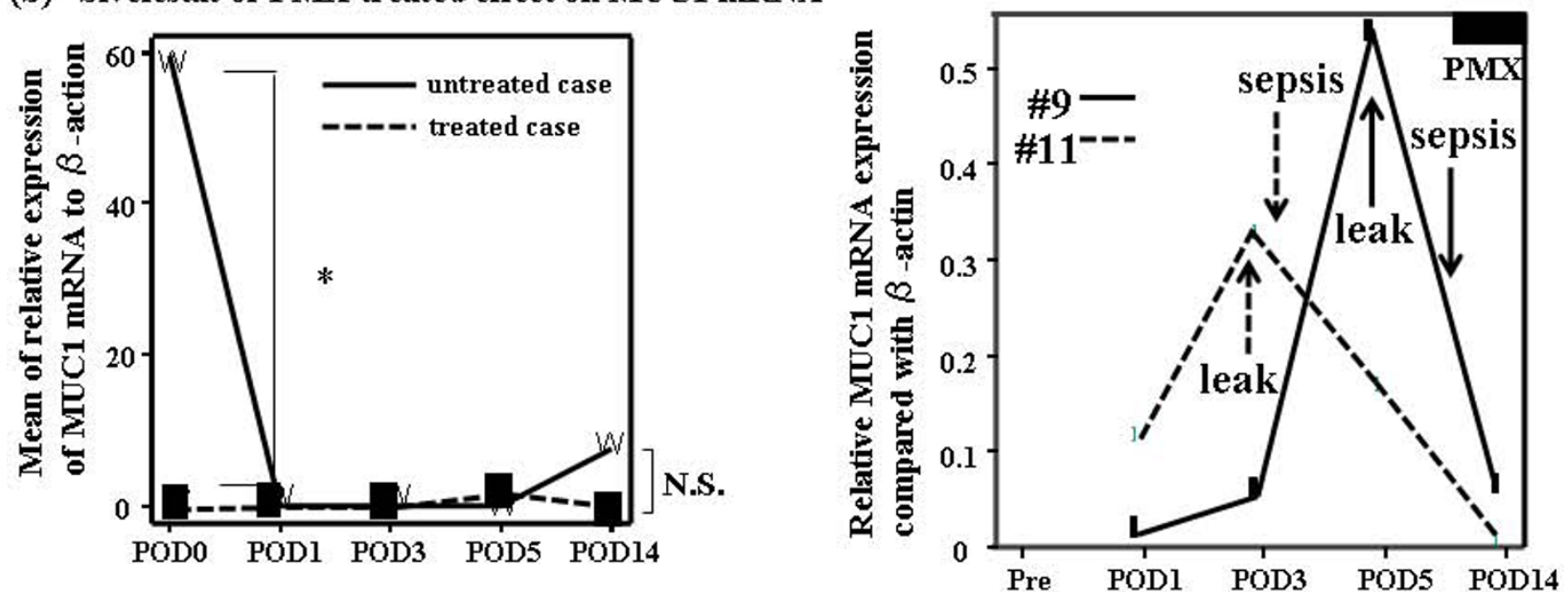

Figure 2 Correlation between IL-6 mRNA expression and clinical parameters (panel a) and effects of Sivelestat or PMX-treatment on MUC1 mRNA (panel b). (a) (left) (a) Kaplan-Meier plot for two conditions (IL-6 mRNA during operation is classified as categorized more or less than 5900) associated with the clinical course of the patients. If the IL-6 mRNA was downregulated to $<5900$, the cumulative proportion had a tendency to increase $(p=0.0505)$, resulting in a shorter period of ventilator dependence. Solid line and dotted line refer to $<5900$ and $>5900$, respectively. (right) If IL-6 mRNA was downregulated to $<5900$, the cumulative proportion was improved significantly $(p=0.0062)$, resulting in a shorter ICU stay. (b) To describe the therapeutic effects of gene expression on prognosis, the effect on MUC1 mRNA of treatment with sivelestat(left) or a polymyxin B-immobilized fiber column (PMX) (right) are depicted. Dotted line and solid line refer to sivelestat-treated $(n=13)$ and untreated $(n=14)$ patients, respectively. In both cases, the mean value of MUC1 mRNA expression relative to $\beta$-action mRNA is shown. (left) Sivelestat caused a significant change in the genes of interest (Table 5). However, it had no significant influence on prognosis (recovery from SIRS). *: $p<0.05$, N.S.: not significant. (right) Clinical courses in two PMX-treated cases (\#9: solid line and \#11: dotted line) are shown. There were no significant relationships between any of the genes and the therapeutic modalities required. Relative MUC1 mRNA expression compared with $\beta$-actin mRNA is plotted. 


\section{(a) IL-6 expression in serum}

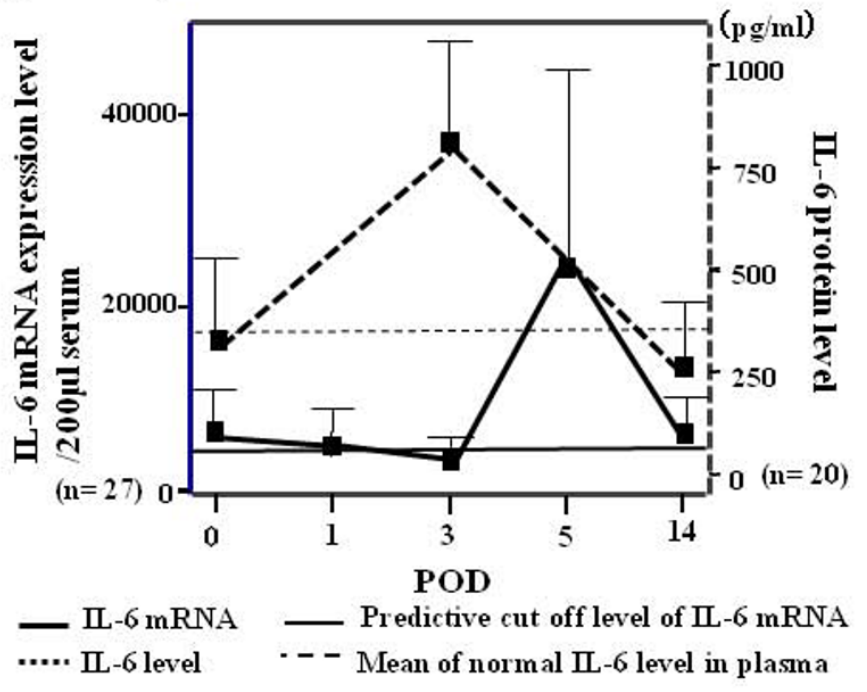

(b) ROC curve analysis

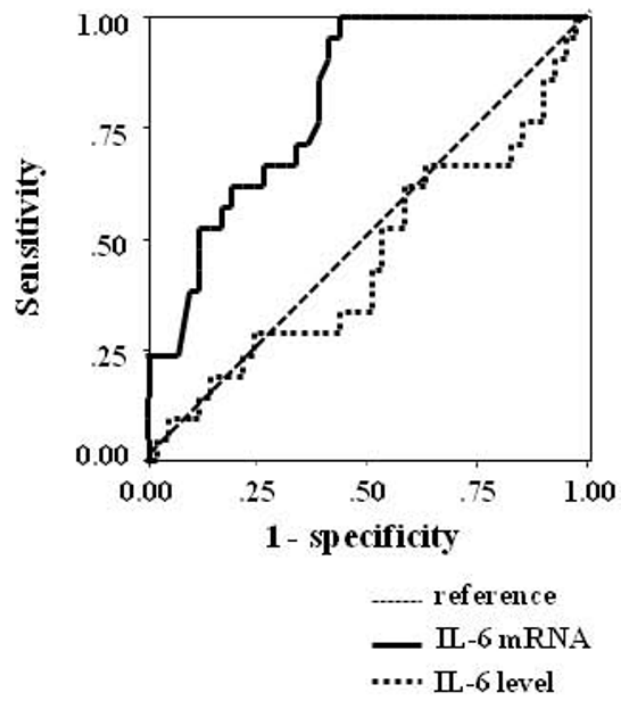

(c) AUC of each biomarker in ROC curve analysis

\begin{tabular}{c|ccccc}
\hline Biomarker & $\begin{array}{c}\text { Area Under } \\
\text { Curve }\end{array}$ & $\begin{array}{c}\text { Standard } \\
\text { Error }\end{array}$ & $\begin{array}{c}\text { Asymptotic } \\
\text { significant } \\
\text { probability }\end{array}$ & \multicolumn{2}{c}{ asymptotic 95\% CI } \\
\cline { 5 - 7 } lower limit & upper limit \\
\hline L-6 mRNA & .809 & .054 & .000 & .704 & .914 \\
L-6 & .453 & .080 & .547 & .296 & .610 \\
\hline
\end{tabular}

Figure 3 IL- 6 mRNA expression and IL- 6 protein level. IL-6 mRNA expression and the IL-6 protein level were evaluated using expression profiles and receiver operating characteristic (ROC) curve analysis. (a) Transcriptional $(n=27)$ and translational $(n=20)$ profiles of IL-6 in serum are shown from POD 0 to 14 (Cl: 95\%), based on the relative expression ratio compared with $\beta$-actin mRNA. Bold solid line, bold dotted line, solid line, and dotted line depict IL-6 mRNA, IL-6, predictive cut-off level of IL-6 mRNA and mean of normal IL-6 level in plasma, respectively. (b) ROC curve analysis drawn between IL-6 mRNA and IL-6. Bold solid line, bold dotted line, dotted line, and solid line refer to IL-6 mRNA, IL-6, mean of normal IL-6 level in plasma, and predictive cut-off level of IL-6 mRNA, respectively. (c) SPSS software analysis of the AUC of the ROC curve was 0.809 and 0.453 for IL-6 mRNA and IL-6, respectively.

the predictive cut-off value of IL-6 mRNA was 3400 as a relative ratio to the $\beta$-actin copy number.

The stepwise analysis is shown in Table 4, suggesting that a high level of IL- 6 mRNA at POD 0 is an independent indicator of poor prognosis (as are days of ventilator dependence, days of ICU stay, and days of SIRS ( $\mathrm{p}<$ 0.0001); a high level at POD3 predicted the onset of pneumonia $(p=0.021)$. Days of ventilator dependence, days of ICU stay, and SIRS days were independent factors influencing prognosis ( $\mathrm{p}<0.05$; data not shown). A significant reduction in mortality was seen by gene expression changes on POD 14 ( $\mathrm{p}<0.001$ by one-way ANOVA). Upregulation of VWF and TGF- 31 mRNA intraoperatively correlated with mortality $(\mathrm{p}=0.0021$ and 0.009). POD 1 upregulation of PDGFA, ERG1, and HMGB1 mRNA correlated significantly with worse prognosis. ( $\mathrm{p}=0.009,0.004$, and 0.012). At POD 3, NAMPT and MUC1 mRNA were found to be independent prognostic factors for 1-year mortality $(\mathrm{p}=0.007,0.012)$; at POD 14, NAMPT mRNA correlated with mortality at 30 days and 1 year $(\mathrm{p}<0.0001$ and $\mathrm{p}=0.0016)$.

Sivelestat affected suppressive gene expression of CRP, EGR1, MUC1, TNF- $\alpha$, PDGFA, NAMPT, and VWF (Table 5). However, PMX treatment did not improve clinical outcome (Figure 2b). The SOFA score correlated only with days of ventilator dependence and ICU stay ( $p$ $=0.038$ and 0.039, Additional File 2).

$12 / 27$ (44\%) patients experienced anastomotic leak (9 cervical and 3 thoracic, additional file 3). EGR1 and IL-6 mRNA expression correlated with anastomotic leak and pneumonia at POD 3 by regression analysis $(\mathrm{p}=0.021$, Table 4). Furthermore, increased duration of operation, anesthesia, and mechanical ventilation was associated with increased risk of pneumonia $(\mathrm{p}<0.001,0.028$, and 
Table 4 Logistic Regression Analysis of Morbidity and Mortality With Stepwise Selection

\begin{tabular}{|c|c|c|c|c|c|c|c|c|c|c|c|}
\hline & gene & $\mathrm{p}$ value & $\mathbf{R}$ & & gene & $\mathrm{p}$ value & $\mathbf{R}$ & & gene & $p$ value & $\mathbf{R}$ \\
\hline DVD & & & & 1Y-mortality & & & & $6 \mathrm{M}$-mortality & & & \\
\hline POD0 & IL-6 & $<0.0001$ & 0.787 & PODO & IL-6 & 0.016 & 0.69 & PODO & WWF & $<0.0001$ & 0.893 \\
\hline days of ICU sta & & & & & WWF & 0.021 & & & IL-6 & $<0.0001$ & \\
\hline PODO & IL-6 & $<0.0001$ & 0.813 & & TGF- $\beta 1$ & 0.009 & & 30D-mortality & & & \\
\hline days of SIRS & & & & POD1 & PDGFA & 0.009 & 0.71 & PODO & WWF & $<0.0001$ & 1.000 \\
\hline PODO & IL-6 & $<0.0001$ & 0.738 & & ERG1 & 0.004 & & & NAMPT & $<0.0001$ & \\
\hline Pneumonia & & & & & HMGB1 & 0.012 & & POD5 & HMGB1 & $<0.0001$ & 0.993 \\
\hline POD3 & IL-6 & 0.021 & 0.442 & POD3 & NAMPT & 0.007 & 0.63 & & MUC1 & 0.002 & \\
\hline $\mathrm{PaO}_{2} / \mathrm{FiO}_{2}$ ratio & & & & & MUC1 & 0.012 & & POD14 & NAMPT & $<0.0001$ & 1.000 \\
\hline POD1 & MMP9 & 0.034 & 0.409 & POD14 & ERG1 & 0.0016 & 0.59 & & PDGFA & $<0.0001$ & \\
\hline SOFA score & & & & & NAMPT & 0.0016 & & & CRP & 0.015 & \\
\hline POD1 & TGF- $\beta 1$ & 0.005 & 0.528 & & & & & & & & \\
\hline
\end{tabular}

N.A: no applicable; N.S.: not significant. R: correlation coefficient.

DVD: duration of ventilator dependence. Independence variables are MMP9, CRP (pre, POD1, peak), ERG, HMGB1, MUC1, PBEF, PDGFA, TGF- $\beta 1$, TNF- $\alpha$, VWF, IL-6, Sivelestat, PMX, anesthesia and operation time.

0.022, Additional File 2, 4). $\mathrm{PaO}_{2} / \mathrm{FiO}_{2}$ ratio did not correlate with any other gene expressions.

\section{Discussion}

Esophageal cancer is one of the most aggressive malignant tumors of the digestive tract. Post-esophagectomy anastomotic leak and pneumonia are common; furthermore, they prolong ICU stay and contribute to poor

Table 5 One-Way ANOVA Analysis With Respect to Sivelestat

\begin{tabular}{|c|c|c|c|c|}
\hline $\begin{array}{l}\text { Time } \\
\text { course }\end{array}$ & $\begin{array}{l}\text { Genetic } \\
\text { parameters }\end{array}$ & $\begin{array}{l}P \\
\text { value }\end{array}$ & $\begin{array}{l}\text { Contribution to } \\
\text { prognosis }\end{array}$ & $\begin{array}{l}\mathrm{P} \\
\text { value } \\
\end{array}$ \\
\hline \multirow[t]{5}{*}{ POD 1} & EGR1 mRNA & 0.037 & 30D-mortality & 0.032 \\
\hline & MUC1 mRNA & 0.041 & $6 \mathrm{M}$-mortality & 0.001 \\
\hline & PDGFA mRNA & 0.037 & & \\
\hline & TNF- $\alpha$ mRNA & 0.016 & & \\
\hline & WWF mRNA & 0.033 & & \\
\hline \multirow[t]{8}{*}{ POD 3} & CRP mRNA & 0.023 & $6 \mathrm{M}$-mortality & $<0.001$ \\
\hline & EGR1 mRNA & 0.022 & 1Y-mortality & 0.023 \\
\hline & MUC1 mRNA & 0.048 & & \\
\hline & NAMPT mRNA & 0.045 & & \\
\hline & PDGFA mRNA & 0.032 & & \\
\hline & TGF- $\beta 1$ mRNA & 0.016 & & \\
\hline & TNF- $\alpha$ mRNA & 0.020 & & \\
\hline & WWF mRNA & 0.047 & & \\
\hline \multirow[t]{2}{*}{ POD 5} & CRP mRNA & 0.001 & 30D-mortality & 0.032 \\
\hline & TNF- $\alpha$ mRNA & 0.032 & $6 \mathrm{M}$-mortality & 0.001 \\
\hline \multirow[t]{6}{*}{ POD 14} & MMP9 mRNA & 0.047 & 30D-mortality & 0.032 \\
\hline & EGR1 mRNA & 0.034 & 6M-mortality & 0.001 \\
\hline & HMGB1 mRNA & 0.042 & & \\
\hline & NAMPT mRNA & 0.032 & & \\
\hline & TGF- $\beta 1$ mRNA & 0.048 & & \\
\hline & WWF mRNA & 0.032 & & \\
\hline
\end{tabular}

prognosis [48]. It is of paramount importance to diagnose these complications immediately postoperatively, and treat them expeditiously [49].

We investigated gene expression by measuring circulating ribonucleic acids in serum (CRAS), with the hope of discovering early prognostic markers post-esophagectomy. We hypothesized that the expression of certain proinflammatory genes would predict outcome, and in particular that POD 1 levels would help to identify patients at risk for anastomotic leak and pneumonia. Furthermore, we expected that gene expression on POD 14 might predict mortality.

$44 \%$ (33\% cervical and $11 \%$ thoracic) of our patients experienced anastomotic leak, which was greater than that which is reported in the literature (expected less than 10\%) [50]. Cervical leaks were treated conservatively while thoracic leaks were severe and contributed to the high morbidity rate as described in our study. We studied the correlation between mRNA levels and morbidity and mortality. Upregulation of VWF mRNA prognosticated poor clinical condition by multivariate analysis. Upregulation of EGR and NAMPT mRNA at POD 1, 3 and 14 indicates that we should become more clinically astute in the immediate postoperative period. The mean/median/cutoff values of IL- 6 mRNA are $5906 / 2810 / 5900$ and, in Kaplan-Meyer survival analysis; if they did not demonstrate significant value among clinical parameters, we concluded that IL-6 mRNA was not an indicative marker for outcome. However, they did correlate with duration of ventilator dependence and ICU stay (Figure 2).

Duration of ventilator dependence, duration of ICU stay and SIRS expectedly affected 6-month mortality, independent of cancer recurrence. Since these conditions are caused by the severity of the underlying disease, by unexpected immunoreactions, and by iatrogenic 
lung injury in the perioperative period, interpretation of their pathogenesis is complicated. Although the onset of SIRS is critical and can adversely affect recovery, we believe that serum gene expression profiles may reliably predict prognosis because of the mRNA stability; i.e., mRNA levels directly reflect pathophysiology either in real-time or over the past 24 hours.

The changes observed in gene expression was indicative of postoperative clinical course. CRP mRNA was upregulated first, with PDGFA, TNF- $\alpha$ and MUC1 mRNA following by POD 3 . In turn, IL-6, VWF and TGF- $\beta 1$ mRNA were upregulated at POD 5 , then NAMPT, EGR1 and MMP9 mRNA. Thus, gene expression actively evolves after surgery for esophageal cancer. It remains unclear whether these changes occur in other disease states.

Four patients (\#11,13,16, 20) received long-term sivelestat and displayed significant downregulation of NAMPT and MUC1 mRNA ( $p<0.001$ and 0.034 by one-way ANOVA) compared with the 23 patients who did not receive this medication. Four patients $(\# 9,11$, $16,20)$ with sepsis following anastomotic leak or aspiration pneumonia significantly upregulated the same genes $(p<0.001$ and $p=0.025)$, if statistical analysis is weighted against dead outcome. As MUC1 expression correlated with CRP, NAMPT may be a crucial factor in the pro-inflammatory state.

Microarray analysis is inefficient for detecting small amounts of circulating RNA because of the limits of current biotechniques, particularly the requirement for at least $500 \mathrm{ml}$ of blood. We chose candidate genes based on information from previous reports and examined their significance. We identified VWF and TGF- $\beta 1$ as potential predictors of improved prognosis, the latter being an indicator of fibrosis. VWF is a glycoprotein that binds to coagulation factor VIII. It functions as both an antihemophilic factor and a platelet-vessel wall mediator in the blood coagulation system. It is crucial to hemostasis and promotes adhesion of platelets to sites of vascular injury by forming a molecular bridge between the sub-endothelial collagen matrix and platelet-surface receptor complex GPIb-IX-V. Therefore, upregulated VWF may represent unstable hemostasis and reflect damage to endothelial megakaryocytes expressing VWF. In the signaling pathway, VWF interacts with integrins in the extracellular matrix (ECM) and has functions in the complement and coagulation cascades, linking downstream to the inflammatory process or to B cell receptor signaling.

NAMPT is another indicator for prognosis. It is the rate-limiting component in the mammalian nicotinamide adenine dinucleotide (NAD) biosynthesis pathway, and promotes vascular smooth muscle cell maturation and inhibition of neutrophil apoptosis. It was originally thought to be a cytokine that acted on early B-lineage precursor cells or $\mathrm{T}$ cell development, by enhancing the effect of IL-7 and SKP1-CUL1-F-box protein (SCF) on pre-B-cell colony formation. SCF mediates the ubiquitination of proteins involved in cell cycle progression, signal transduction and transcription. PDGFA is also a predictive factor for prognosis. It is activated in IFN $-\gamma /$ IL-10 signaling in keratinocytes via the JAK/STAT pathway and is also involved in signaling via the MAPK cascades, STATs and NF- $\kappa \mathrm{B}$ through its receptor. It contributes to balancing the Th1/Th2 switch by affecting anti-apoptosis and cell proliferation. EGR1 is targeted by Erk, is activated by IL-2 and IL-3 cascades, and targets eukaryotic translation initiation factor $4 \mathrm{E}$ binding protein 1 . Severe inflammatory disease is a critical condition linked to collapse of the Th1/Th2 balance and, from a prognostic standpoint, these genes are upregulated when Th1 cells (producing IL-2, IL-3 and IFN- $\gamma$ ) are dominant over Th2 cells (generating IL-10 and leading to IL-7 activation). This suggests that novel therapeutic antibody drugs for SIRS may be found in the study of these cytokines.

TGF- $\alpha$ mRNA in serum has previously been described as a prognosticator in fulminant hepatitis [11] although this was not the case in our study. Expression of CRP mRNA correlated with the serum CRP level at all clinical phases, although we could not optimize the reaction condition for detecting CRP mRNA. We reconfirmed that CRP is an excellent marker for acute inflammation, but not for prognosis and SIRS onset. These prognostic genes for SIRS or sepsis may be useful in intensive care settings for earlier detection of decompensation [51].

\section{Conclusion}

We proposed measuring an inflammatory gene expression profile perioperatively in patients undergoing surgery for esophageal cancer. VWF and TGFB1 mRNA at POD 0 were prognostic biomarkers for mortality. IL-6 mRNA was a significant biomarker for the onset of severe inflammatory conditions and its upregulation throughout the postoperative period predicted poor prognosis. We could not distinguish SIRS from bacteremia. Further prospective studies on individual gene expression profiles are necessary to clarify their influence on prognosis in esophageal cancer.

\section{Additional material}

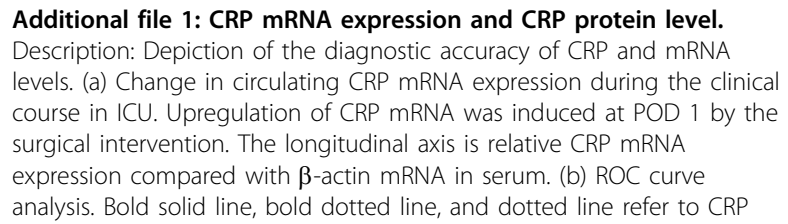

Additional file 1: CRP mRNA expression and CRP protein level. Description: Depiction of the diagnostic accuracy of CRP and mRNA levels. (a) Change in circulating CRP mRNA expression during the clinical course in ICU. Upregulation of CRP mRNA was induced at POD 1 by the surgical intervention. The longitudinal axis is relative CRP mRNA expression compared with $\beta$-actin mRNA in serum. (b) ROC curve analysis. Bold solid line, bold dotted line, and dotted line refer to CRP 
level, CRP mRNA and reference, respectively. (c) AUC of the ROC curve analysis of each biomarker. The sensitivities of CRP level and CRP mRNA were $98.6 \%$ and $74.1 \%$, respectively. CRP level was superior to CRP mRNA as an inflammatory biomarker.

\section{Additional files 2: Correlation between GE and clinical parameters}

To examine the relationship between clinical parameters and $\mathrm{GE}$, the Pearson correlation analysis test was performed from POD 0 to POD 14 DVD: duration of ventilator dependence.

Additional file 3: Surgical treatment and an anastomotic leakage Surgical treatment and an anastomotic leakage are shown.

Additional file 4: Correlation between GE and clinical parameters. To examine the relationship between clinical parameters and GE, the Pearson correlation analysis test was performed from POD 0 to POD 14 DVD: duration of ventilator dependence.

\section{Abbreviations}

ICU: intensive care unit; MMP9: matrix metallopeptidase 9; CRP: $C$ reactive protein; EGR1: early growth response 1; HMGB1: high-mobility group box 1; MUC1: mucin 1; NAMPT (PBEF1): nicotinamide phosphoribosyltransferase; PDGFA: platelet-derived growth factor alpha polypeptide; TGF- $\beta$ 1: transforming growth factor beta 1; TNF- $\alpha$ : tumor necrosis factor-alpha; WW: von Willebrand factor; ARDS: acute respiratory distress syndrome; SIRS: systemic inflammatory response syndrome; SNISIRS: severe non-infectious systemic inflammatory response syndrome; GE: gene expression; SOFA score: sequential organ failure assessment score; SS: severe sepsis; DVD: duration of ventilator dependence; CRAS: circulating ribonucleic acids in serum; ALI: acute lung injury; PMX: polymyxin B-immobilized fiber column; MUC1: mucin 1; IL-6: interleukin-6; ECM: extracellular matrix; NAD: nicotinamide adenine dinucleotide; SCF: SKP1-CUL1-F.

\section{Acknowledgements}

This study was financially supported by a Grant-in-Aid for Scientific Research from the Ministry of Education, Science. No conflicts of interest.

\section{Author details}

'Division of Anesthesiology and Critical Care Medicine, Tottori University School of Medicine, Nishicho 36-1, Yonago, Tottori 683-8503, Japan. '²ivision of Pharmacotherapeutics, Department of Pathophysiological and Therapeutic Science, Faculty of Medicine, Tottori University, Nishicho 86, Yonago, Tottori 683-8503, Japan. ${ }^{3}$ Division of Anesthesiology, Tottori Red Cross Hospital, 117 Shoutokucho, Tottori, Tottori 680-8517, Japan. ${ }^{4}$ Division of Anesthesiology, Shimane Prefectural Central Hospital, 4-1-1 Himehara, Izumo, Shimane 6938555, Japan. ${ }^{5}$ Division of Molecular and Genetic Medicine, Department of Genetic Medicine and Regenerative Therapeutics, Tottori University, Nishicho 86, Yonago, Tottori 683-8503, Japan.

\section{Authors' contributions}

ST and MN designed experiments, interpreted data and drafted the manuscript; TH and HT managed patient samples, prepared RNA; ZW and XW performed real-time PCR; YO, JH, YI and GS provided detailed ideas and discussions.

All authors have read and approved the final manuscript.

\section{Competing interests}

The authors declare that they have no competing interests.

Received: 31 March 2010 Accepted: 22 October 2010 Published: 22 October 2010

\section{References}

1. Milberg JA, Davis DR, Steinberg KP, et al: Improved survival of patients with acute respiratory distress syndrome: 1983-1993. JAMA 1995, 273:306-309

2. Lewandowski K, Metz J, Deutschmann C, et al: Incidence, severity, and mortality of acute respiratory distress syndrome. Am J Respir Crit Care Med 1995, 151:1121-1125.
3. Mink SN, Light RB, Cooligan T: Effect of PEEP on gas exchange and pulmonary perfusion in canine lobar pneumonia. J Appl Physiol 1981, 50:517-523.

4. Nahum A, Hoyt J, Schmitz L, et al: Effect of mechanical ventilation strategy on dissemination of intratracheally instilled Escherichia coli in dogs. Crit Care Med 1997, 25:1733-1743.

5. Ferreira FL, Bota DP, Bross A, et al: Serial evaluation of the SOFA score to predict outcome in critically ill patients. JAMA 2001, 286:1754-1758.

6. Tang BM, McLean AS, Dawes IW, et al: Gene-expression profiling of peripheral blood mononuclear cells in sepsis. Crit Care Med 2009, 37:882-888.

7. Ulloa L, Tracey KJ: The "cytokine profile": a code for sepsis. Trends Mol Med 2005, 11(2):56-63.

8. Chen $\mathrm{XQ}$, Bonnefoi $\mathrm{H}$, Pelte MF, et al: Telomerase RNA as a detection marker in the serum of breast cancer patients. Clin Cancer Res 2000, 6:3823-3826.

9. Tsui NB, Ng EK, Lo YM: Stability of endogenous and added RNA in blood specimens, serum, and plasma. Clin Chem 2002, 48:1647-1653.

10. Miura N, Hasegawa J, Shiota G: Serum messenger RNA as a biomarker and its clinical usefulness in malignancies. Clin Med Oncol 2008, 2:511-527.

11. Miura N, Kabashima H, Shimizu M, et al: Clinical impact of serum transforming growth factor-alpha mRNA as a predictive biomarker for the prognosis of fulminant hepatitis. Hepatol Int 2008, 2:213-221.

12. Wong $F H$, Huang $C Y$, Su $L$, et al: Combination of microarray profiling and protein-protein interaction databases delineates the minimal discriminators as a metastasis network for esophageal squamous cell carcinoma. Int J Oncol 2009, 34:117-128.

13. El-Kenawy Ael-M, Lotfy M, El-Kott A, et al: Significance of matrix metalloproteinase 9 and CD34 expressions in esophageal carcinoma: correlation with DNA content. J Clin Gastroenterol 2005, 39:791-794.

14. Gu ZD, Li JY, Li M, Gu J, et al: Matrix metalloproteinases expression correlates with survival in patients with esophageal squamous cell carcinoma. Am J Gastroenterol 2005, 100:1835-1843.

15. Ngiam N, Post M, Kavanagh BP: Early growth response factor-1 in acute lung injury. Am J Physiol Lung Cell Mol Physiol 2007, 293:L1089-1091.

16. Hoetzel A, Dolinay T, Vallbracht $\mathrm{S}$, et al: Carbon monoxide protects against ventilator-induced lung injury via PPAR-gamma and inhibition of Egr-1. Am J Respir Crit Care Med 2008, 177:1223-32.

17. Ingram JL, Antao-Menezes A, Mangum JB, et al: Opposing actions of Stat1 and Stat6 on IL-13-induced up-regulation of early growth response-1 and platelet-derived growth factor ligands in pulmonary fibroblasts. J Immunol 2006, 177:4141-4148.

18. El Gazzar M, Yoza BK, Chen X, et al: Chromatin-specific remodeling by $\mathrm{HMGB} 1$ and linker histone $\mathrm{H} 1$ silence proinflammatory genes during endotoxin tolerance. Mol Cell Biol 2009.

19. Kornblit B, Munthe-Fog L, Madsen HO, et al: Association of HMGB1 polymorphisms with outcome in patients with systemic inflammatory response syndrome. Crit Care 2008, 12:R83.

20. Suda K, Kitagawa Y, Ozawa S, et al: Serum concentrations of high-mobility group box chromosomal protein 1 before and after exposure to the surgical stress of thoracic esophagectomy: a predictor of clinical course after surgery? Dis Esophagus 2006, 19:5-9.

21. Nakashima T, Yokoyama A, Ohnishi H, et al: Circulating KL-6/MUC1 as an independent predictor for disseminated intravascular coagulation in acute respiratory distress syndrome. J Intern Med 2008, 263:432-439.

22. Sato $\mathrm{H}$, Callister ME, Mumby S, et al: $\mathrm{KL}-6$ levels are elevated in plasma from patients with acute respiratory distress syndrome. Eur Respir J 2004, 23:142-145.

23. Guillem P, Billeret V, Buisine MP, et al: Mucin gene expression and cell differentiation in human normal, premalignant and malignant esophagus. Int J Cancer 2000, 88:856-861.

24. Busso N, Karababa M, Nobile M, et al: Pharmacological inhibition of nicotinamide phosphoribosyltransferase/visfatin enzymatic activity identifies a new inflammatory pathway linked to NAD. PLOS ONE 2008, 3: e2267.

25. Van Gool F, Gallí M, Gueydan C, et al: Intracellular NAD levels regulate tumor necrosis factor protein synthesis in a sirtuin-dependent manner. Nat Med 2009, 15:206-210.

26. Rongvaux A, Galli M, Denanglaire S, et al: Nicotinamide phosphoribosyl transferase/pre-B cell colony-enhancing factor/visfatin is required for 
lymphocyte development and cellular resistance to genotoxic stress. $J$ Immunol 2008, 181:4685-4695.

27. Samal B, Sun Y, Stearns G, Xie C, Suggs S, McNiece I: Cloning and characterization of the CDNA encoding a novel human pre-B-cell colonyenhancing factor. Mol Cell Biol 1994, 14:1431-1437.

28. Li J, Hoyle GW: Overexpression of PDGF-A in the lung epithelium of transgenic mice produces a lethal phenotype associated with hyperplasia of mesenchymal cells. Dev Biol 2001, 239:338-349.

29. Gowan SE, Grossmann RE, Kimani PW, et al: Platelet-derived growth factor receptor-alpha-expressing cells localize to the alveolar entry ring and have characteristics of myofibroblasts during pulmonary alveolar septal formation. Anat Rec (Hoboken) 2008, 291:1649-1661.

30. Aizawa K, Suzuki T, Kada N, et al: Regulation of platelet-derived growth factor-A chain by Krüppel-like factor 5: new pathway of cooperative activation with nuclear factor-kappaB. J Biol Chem 2004, 279:70-76

31. Budinger GR, Chandel NS, Donnelly HK, et al: Active transforming growth factor-beta1 activates the procollagen I promoter in patients with acute lung injury. Intensive Care Med 2005, 31:121-128.

32. Fahy RJ, Lichtenberger $F$, McKeegan $C B$, et al: The acute respiratory distress syndrome: a role for transforming growth factor-beta 1. Am J Respir Cell Mol Biol 2003, 28:499-503.

33. Wu HP, Chen CK, Chung $K$, et al: Plasma transforming growth factorbeta1 level in patients with severe community-acquired pneumonia and association with disease severity. J Formos Med Assoc 2009, 108:20-27.

34. Ware LB: Prognostic determinants of acute respiratory distress syndrome in adults: impact on clinical trial design. Crit Care Med 2005, 33:S217-222.

35. Russell J: Genetics of coagulation factors in acute lung injury. Crit Care Med 2003, 31:S243-7.

36. Hamacher J, Lucas R, Lijnen HR, et al: Tumor necrosis factor-alpha and angiostatin are mediators of endothelial cytotoxicity in bronchoalveolar lavages of patients with acute respiratory distress syndrome. Am J Respir Crit Care Med 2002, 166:651-656.

37. Ware LB, Conner ER, Matthay MA: von Willebrand factor antigen is an independent marker of poor outcome in patients with early acute lung injury. Crit Care Med 2001, 29:2325-2331.

38. Flori HR, Ware LB, Milet $M$, et al: Early elevation of plasma von Willebrand factor antigen in pediatric acute lung injury is associated with an increased risk of death and prolonged mechanical ventilation. Pediatr Crit Care Med 2007, 8:96-101.

39. García-Fernández N, Montes R, Purroy A, et al: Hemostatic disturbances in patients with systemic inflammatory response syndrome (SIRS) and associated acute renal failure (ARF). Thromb Res 2000, 100:19-25.

40. Fujihashi $\mathrm{K}$, Kono $\mathrm{Y}$, Kiyono $\mathrm{H}$ : Effect of IL6 on B cells in mucosal immune response and inflammation. Res Immunol 1992, 143(7):744-749.

41. Bernard GR, Artigas A, Brigham KL, et al: The American-European Consensus Conference on ARDS. Definitions, mechanisms, relevant outcomes, and clinical trial coordination. Am J Respir Crit Care Med 1994, 149:818-824

42. Bones RC, Balk RA, Cerra FB, et al: Definitions for sepsis and organ failure and guidelines for the use of innovative therapies in sepsis. Chest 1992, 101:1644-1655.

43. Miura N, Shiota G, Nakagawa T, et al: Sensitive detection of hTERT mRNA in the serum of patients with hepatocellular carcinoma. Oncology 2003, 64:430-434.

44. Miura N, Maeda Y, Kanbe T, et al: Serum human telomerase reverse transcriptase messenger RNA as a novel tumor marker for hepatocellular carcinoma. Clin Cancer Res 2005, 11:3205-3209.

45. Miura N, Nakamura $\mathrm{H}$, Sato R, et al: Clinical usefulness of serum telomerase reverse transcriptase (hTERT) mRNA and epidermal growth factor receptor (EGFR) mRNA as a novel tumor marker for lung cancer. Cancer Sci 2006, 97:1366-1373.

46. Livak KJ, Schmittgen TD: Analysis of relative gene expression data using real-time quantitative PCR and the 2(-Delta Delta $C(T)$ ) method. Methods 2001, 25(4):402-408.

47. Vincent J, Ferreira F, Moreno R: Scoring systems for assessing organ dysfunction and survival. Crit Care Clin 2000, 16:353-366.

48. Wright $C D$, Kucharczuk JC, O'Brien SM, et al: Predictors of major morbidity and mortality after esophagectomy for esophageal cancer: a Society of Thoracic Surgeons General Thoracic Surgery Database risk adjustment model; Society of Thoracic Surgeons General Thoracic Surgery Database. J Thorac Cardiovasc Surg 2009, 137(3):587-595.
49. Vincent Jean-Louis, Rello Jordi, Marshall John, et al: International study of the prevalence and outcomes of infection in intensive care units. JAMA 2009, 302:2323-2329.

50. Urschel JD: Esophagogastrostomy anastomotic leaks complicating esophagectomy: a review. Am J Surg 1995, 169(6):634-40.

51. Bouadma Lila, Luyt Charles-Edouard, Tubach Florence, et al: Use of procalcitonin to reduce patients' exposure to antibiotics in intensive care units (PRORATA trial): a multicentre randomized controlled trial. Lancet 2010, 375:463-474.

doi:10.1186/1479-5876-8-103

Cite this article as: Takahashi et al: Prognostic impact of clinical coursespecific mRNA expression profiles in the serum of perioperative patients with esophageal cancer in the ICU: a case control study. Journal of Translational Medicine 2010 8:103.

\section{Submit your next manuscript to BioMed Central and take full advantage of:}

- Convenient online submission

- Thorough peer review

- No space constraints or color figure charges

- Immediate publication on acceptance

- Inclusion in PubMed, CAS, Scopus and Google Scholar

- Research which is freely available for redistribution 